\title{
Port Logistic Support Areas (PLSA) for exporting grains: An exploratory case-study in the largest port in Latin America
}

\author{
Clayton Gerber Mangini ${ }^{1,2[0000-0001-9107-5435]}$, Irenilza de Alencar Nääs² [0000-0003-0663- \\ 9377], Antônio Carlos Estender 1,3[0000-0002-0547-1077], Meykson Rodrigues Alves Cor- \\ deiro $^{1 \text { [0000-0002-1837-8816] }}$ and Agnaldo Vieira da Silva ${ }^{1[0000-0002-9089-8023]}$, \\ ${ }^{1}$ Graduate Studies in Production Engineering - Universidade Paulista, São Paulo SP 04026- \\ 002, Brazil \\ clayton.mangini@gmail.com \\ irenilza@gmail.com \\ estender@uol.com \\ meykson_cordeiro@hotmail.com \\ agnaldo.silva@docente.unip.br \\ ${ }^{2}$ FATEC Baixada Santista - Rubens Lara. 11045-908, SP, Brazil \\ clayton.mangini@gmail.com \\ ${ }^{3}$ FATEC Franco da Rocha - São Paulo. 04026-002, SP, Brazil \\ estender@uol.com
}

\begin{abstract}
The Port Logistic Support Areas (PLSA) receive and carry out the sorting of trucks that have the aim to reach the maritime terminals of the Port of Santos. Such areas are vital for the logistics of grains exporting as they regulate the flow of these vehicles, avoiding logistic bottlenecks and maintaining an appropriate balance within the city. This research aims at analyzing the prospects of PLSA in the face of new credentials carried out by the different Port Authorities in several parts of Brazil since there is a fall down in the trade of these companies. An exploratory method was used to analyze the truck movement data during the years of 2015, 2016, and 2017. It was considered the in-flow of grain carrying trucks facing the out-going from São Paulo city to the port of Santos. A reduction of more than $30 \%$ in vehicle movement was verified, from Jan 2015 to Dec 2017, where some determining factors were responsible for this reduction, as the use of other ports to the outflow of harvesters and the use of the rail modal, which leads to the questioning of the real need for the accreditation of new PLSAs.
\end{abstract}

Keywords: grain transportation; logistics;

\section{Introduction}

The Port of Santos is the largest port complex in Latin America and accounts for almost a third of Brazilian trade [1]. Much of this movement is directly related to agribusiness, where Brazil stands out on the world stage as one of the great exporters of solid vegetable bulks. The PLSA receive and carry out trucks with access to the grain terminals, and play an essential role for port logistics since the accesses on the left, and right banks of the Port of Santos and their respective areas do not favor heavy traffic due to lack of space.

The new accreditation of regulatory support areas carried out by Brazilian port authorities seems to be against the movement of trucks, since according to the objective 
of this research, there is a deficit of more of $30 \%$ in the occupation of these places, caused by several reasons, such as the spraying of these vehicles among the other PLSA. Therefore, it is noticed that the trend is for a decrease in the movement of trucks in the PLSA, with an ample supply of vacancies that will not be occupied. Some factors such as the growth and modernization of the ports of Arco Norte, which are widely used in the export of soybeans and corn, attract demand to the north of the country, thus causing damages to the companies that exploit these areas, and in many cases activities. In such a way, the port authorities should evaluate the form the accreditation of new parking places is made based on the demand and existing spots warrantying the PLSA sustainability.

The present study aimed to analyze the perspectives of the companies that carry out such support areas, facing the new accreditations. Data on the movement of a company that has parking areas in a neighbor city of Santos (Cubatão), in the years 2015 to 2017 were analyzed.

\section{$2 \quad$ Literature Review}

Over the past decade, companies involved in grain production and logistics have become highly competitive and technologically advanced, with many opportunities and risks arising in this operation. Difficulties in managing national and international grain logistics are uncertainties faced by logistic companies of solid plant bulk, as they depend on the seasonality of production and environmental factors such as climate, disease, and pests [2].

According to [3], Brazil is one of the world's largest exporters of soy and corn. Therefore, much of the harvest is negotiated with other countries and mainly drained by the Brazilian ports. Since the plantation areas are mostly located in the Center-West of the country, logistical transport of these bulk cargoes has become a challenge, since Brazil is a continental extension country with only a few railroad options. A series of factors, ranging from the research of new varieties of plants, agricultural defenses, machinery, management and efficiency of the producers, led to a growing increase in the production of Brazilian grains [4].

The use of parking areas for trucks staying prior to shipment of grains [5] is pointed out by the Brazilian ports' authority (SEP in Portuguese) as an outlet to minimize the impacts of the export of the grain production by the Port of Santos in the cities of the coastal line (Baixada Santista). The idea is to contain the massive flow of trucks that are heading towards the bulk terminals before the vehicles go down to the Sierra (that separates the metropolitan area of São Paulo to the coast), to avoid causing heavy traffic on the roads that attend the municipalities of the region. Only trucks transporting grain to export are required to make use of the PLSA before going to the terminals [5]. According to [6], the parking areas are those where the vehicles with cargo stop, while they wait for the release of the terminal that will receive their loads. However, it also serves to relieve traffic near the Port of Santos, chaired by trucks parked on highways accessing Santos, since there is not an appropriate place to wait for final positioning.

From the perspective of transporting cargo from the point of departure to the Santos dock, the route planning must be useful, since in this way the trucks are received at the destination terminal only when there are space and service area available. Nevertheless, 
this practice exists in some situations; since the large portion of the terminals uses these cargo vehicles as a moving warehouse [6]. The parking pockets are like places of obligatory stop for the truck drivers towards the Baixada Santista. These spaces have intelligent devices that make a direct connection to the terminals and the Port of Santos. Such initiative allows the checking of the duration of the vehicle's movement and the precise period to check the documentation and unloading. Afterward, the truck moves to the port terminal [6].

In the PLSA this monitoring is carried out by the Operational Control Center (OCC), where information on the occupancy rate of the area, vehicle release, hourly movement, and other relevant management information is controlled and released to the supervisory institution [5]. The PSLA is like an organized warehouse, with its release through free areas and the terminal's ability to operate. These warehouses allow a constant and organized flow in the shipment of cargoes at the Santos quay [7]. According to [6], a large portion of the terminal users do not feel comfortable leaving the vehicles away from the port area (in highway areas) due to reasons such as:

a) The deteriorated roads, causing unforeseen events on the way to the destination of the cargo;

b) The expenses as a consequence of unpaired movement and the security of what is being transported.

Bulk ships do not have to schedule their arrival at the terminals, that is, this interferes with the organization for the reception of the vehicles since the terminals must be predisposed to attend to the ships that dock. According to the port operators, when the terminal is not loaded, it will have to bear a high cost for the delay in operating the ships [6]. The best thing would be to channel the information system into a single parking area, which would substantially reduce the cost of the operation. However, there is no technical restriction to use a defined area system, since it is of the utmost importance that the patios are connected. For some authors, the per-stroke times from the parking to the Santos pier of each truck vary according to where it is parked since the transcarriers might use more than one pocket for the unloading activity.

Another way of transporting these bulk grains for export, without compromising the Port-city relationship, is by the rail mode. Rail transport accounts for about $27 \%$ of the cargo handled at the Port of Santos, which has an internal railway network with $100 \mathrm{~km}$ of extension [1]. One of the most benefited cargoes is agribusiness since $53 \%$ are transported through the railways located in the port of Santos.

\section{Methods}

The company chosen for this study is the pioneer in the state of São Paulo in the operation of truck sorting and parking areas in access to the port of Santos. Also, it has the largest area, with $443 \times 10^{3} \mathrm{~m}^{2}$, with the most significant number of available spaces, with 1250 areas (Figure 1). It is, therefore, an essential reference for the operation of PLSA in Brazil. 


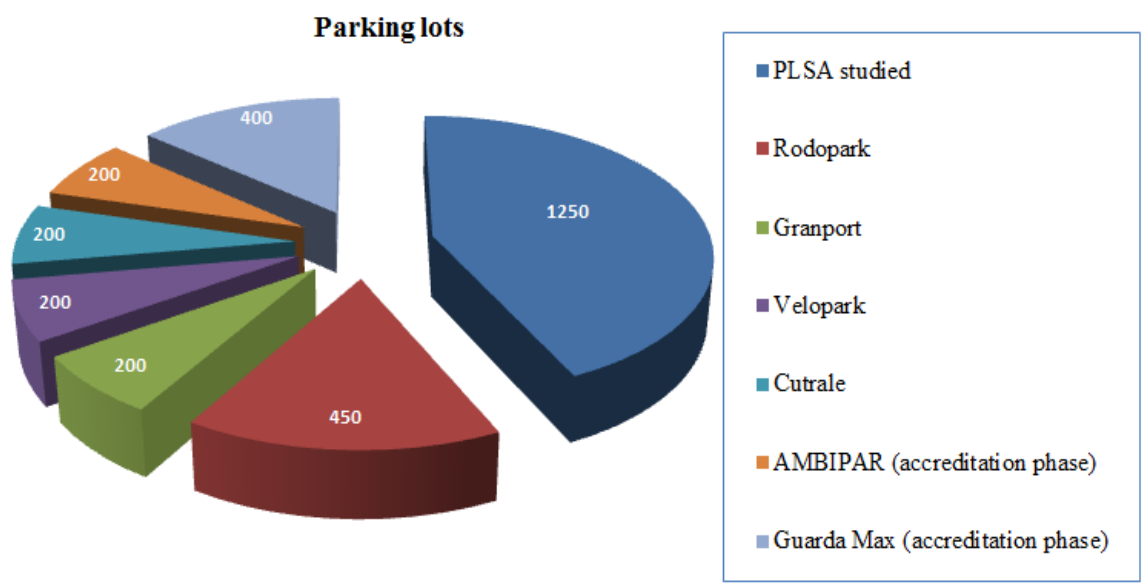

Fig. 1. The unoccupied capacity of logistic parking lots (PLSA, area) of the São Paulo State in 2018. Source: [5]

Figure 1 shows a comparison of the number of parking spots available amongst the studied company and other of the same segment. Such information indicates the representativity of each company in the Porto d Santos.

The present research is an exploratory case-study in a PLSA located in the county of Cubatão - SP, in the metropolitan area of Santos. An analysis of the procedure of the PLSA was carried out for 36 months, from January 2015 to December 2017. The data-set was organized using the number of trucks accessing the company every month. Such information is stored by Syslog (the software used by the studied company) which receives the data in an automated way by the Optical Character Recognition (OCR), made available monthly in the form of a report.

A case-study was adequate in the present study since the research requires a situational explanation and some detailing $[8 ; 9 ; 10]$.

The output of the vehicles in the studied PLSA system should be performed for all trucks entering the company. To be operationalized such exit in the system, the driver presents/displays a ticket and find the departure of the truck in the system using a bar code. Thus, by controlling the entrances and exits of the trucks in the PLSA in an automated way, OCR forwards such information to the company's software, there is an accuracy of the information of satisfactory movement for the gathering and study of this data. The movement of the vehicles is directly linked to the grain harvest companies, mainly coming from the western area of the country, where the port of Santos has a significant portion for the flow to the main world markets.

\section{$4 \quad$ Result and Discussion}

The company object of the study established a system in its work instructions for the entrance of the trucks in the PLSA, and in this way to account the flow and movement of the vehicles in its patio. The driver of the truck is directed to the automated entrance gates (01 to 10$)$, where after stopping in front of the gate, the OCR system reads the 
vehicle's license plate. The OCR performs the reading of the board and searches the operation of the patio regulator studied, the link/scheduling using the captured number.

After verifying the previously performed scheduling, a message is generated by the system releasing the vehicle. Figure 2 shows the timeline of vehicles in the current study PLSA, from January 2015 to December 2017 . Vehicle volume decreased by $31 \%$.

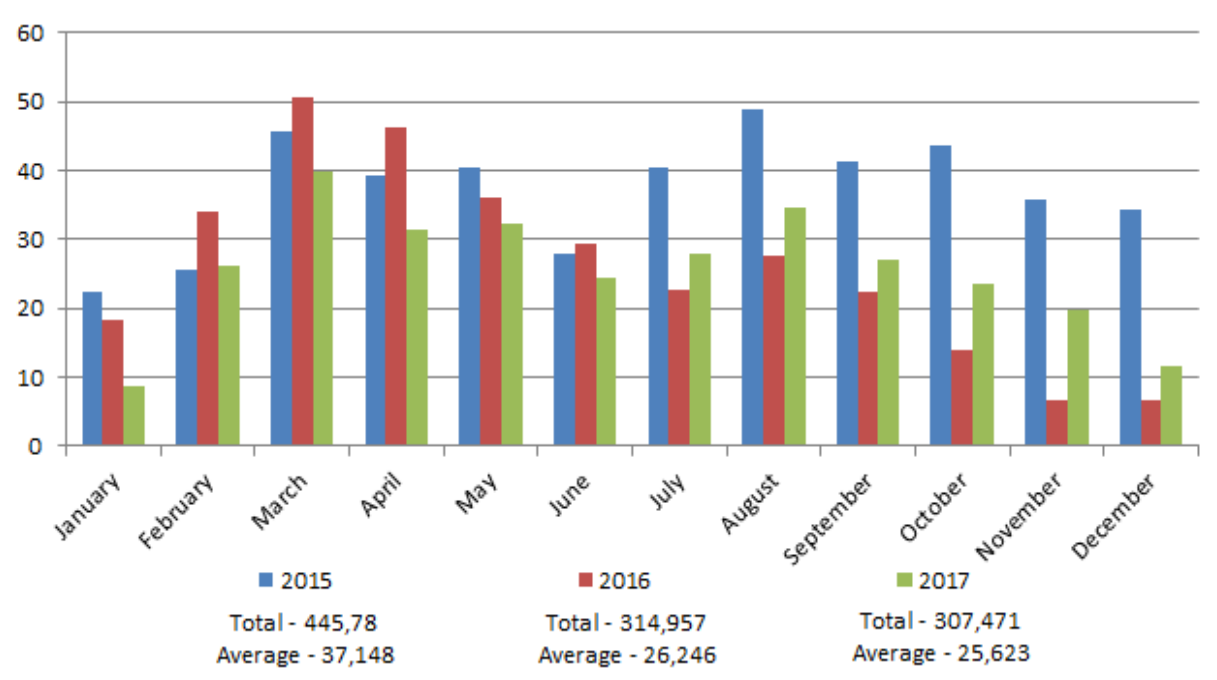

Fig 2. Number of vehicles in movement (2015-2017)

The decrease evidenced during these years occurs from the second semester of 2016, where it refers to a low movement related to the sugar harvest. However, according to CODESP, sugar exports in bulk in the year 2016 obtained an increase of 11.8\%, indicating that the sugar terminals have used, as an alternative, the use of own regulatory yards, such as COSAN, which has a logistics division that includes an exclusive truck sorting yard to meet the company's demand.

Another decrease was observed in the first half of 2017, where it refers to a low movement of soybean and corn crops. The Brazilian export of bulk soybeans and corn in the accumulated 2017 obtained $13.6 \%$ and $80.5 \%$ increase respectively, signaling that some of the vehicles occupied the new regulatory yards opened and accredited by CODESP recently, as the municipalities of Santos and Guarujá [1]. The trend for the next years is to continue falling, since until March 2018 the average movement reached 23,413 vehicles, representing a reduction of $8.62 \%$ compared to 2017 .

The importance of PLSA is undeniable and necessary in the region that permeates the port of Santos. The Port Authorities, observing the positive operational results both on the highways and in the urban mobility of the port cities, increased the accreditation of new PLSA increasingly the offer of vacancies for trucks in these companies. A fact to be considered is that, according to the Brazilian Ministry of Agriculture, Livestock and Supply (MAPA), part of the exports is being destined to the ports of the Northern Arch (Itaquatiara, Itaqui, Santarém, Barbacena and Salvador), accounting today for 
$24 \%$ of all volume exported by Brazil, with a focus mainly on soybean and corn harvests.

Another point to consider is the increase in exports by the ports of Paranaguá and Antonina (located in the Southern region of the country). According to the Port Administration of Paranaguá and Antonina (APPA), in 2017, there was an increase in traffic in $14.2 \%$ compared to the previous year, reaching a historic result in the region. In 2013, the company Rumo in the city of Rondonópolis (Brazilian Center-West region) its new intermodal terminal, which brought a new reality for the storage availability of the agricultural harvest. It is from such intermodal terminal that the most substantial part of the flow of soybean harvest from the Mato Grosso area departs to the port of Santos. Today the terminal carries, on average, seven trains with eighty wagons per day and moves about $1510^{6}$ tons of soybeans/year. The structure with seven dump trucks and a warehouse with a capacity of $4510^{3}$ tons can receive up to 1,200 trucks/day.

Finally, this research presents the current stage in the PLSA operation studied, indicating that there is still much to do to improve and optimize requirements in this business model. The volume of trucks is undoubtedly important data to be considered in a survey of this relevance in PLSA since there is a significant difference in the flow of vehicles using the system. In this way, this study can serve as a reference to other PLSA, and especially for new companies that intend to be accredited with the Port Authorities.

\section{Conclusion}

The present study indicates that the port authority should have stricter criteria before accrediting a company to operate a PLSA, limiting the number of vacancies of the trucks by region, once all the requirements imposed by legislation are met. In this way, with the supervision of the competent governmental bodies, the prospects of the PLSA in the face of new accreditations will continue to be an essential tool to control the access of trucks with bulk solids to the Port of Santos. Also, the terminal has a PLSA that allows the static parking of 700 trucks, in addition to another 350 internal spaces. Currently, more than 800 jobs are generated in such an enterprise.

The country's largest railroad operator, the company says it has been carrying out a revitalization and logistical expansion work of significant impact on its network, which totals more than $12 \times 10^{3} \mathrm{~km}$ of the railroad. This process comes from the merger with Latin America Logistics (ALL), completed in April 2015. In this way, even the railroad model does not present an expectation of considerable improvement to reduce the movement in the PLSA. The destination of the harvests to other ports and mainly the opening and accreditation of new yards of sorting of trucks by the port authorities become a factor decisive for the functioning of these companies because each year the demand decreases, where it does not become financially and operationally sustainable.

\section{Acknowledgment}

The first author wishes to thank the Coordination of Superior Studies (Capes) for the scholarship. 


\section{References}

1. Porto de Santos. Homepage, http://www.portodesantos.com.br. Accessed 2018/08/17.

2. Wilson, W., Carlson, D., Dahl, B. Logistics and Supply Chain Strategies in Grain Exporting. Agribusiness, vol. 20, n.4, pp. 449-464, (2004).

3. Fioroni, M., Franzese, L., Santana, I., Lelis, P., Silva, C., Telles, G., Quintáns, J., Maeda, F., Varani, R. From farm to port: simulation of the grain logistics in Brazil. Winter Simulation Conference (WSC) pp. 1936 - 1947. (2015).

4. Santos, A., Sproesser, R. Caracterização e avaliação da eficiência dos terminais intermodais brasileiros. Gestão \& Regionalidade - vol. 29, n.87, pp. 47-63. Sept-Dec, 2013.

5. CODESP - Companhia Docas do Estado de São Paulo. Resolução DP n 14.2014, de 3 de fevereiro de 2014. Homepage, http://intranet.portodesantos.com.br/_docs/resolucao/resolucao_4637.pdf. , last accessed 2018/08/17.

6. Pereira, L., Maia, N., Pereira, W. A Importância do Investimento em Pátios Reguladores de Caminhões nos Portos Brasileiros. 15 ${ }^{\text {th }}$ Brazilian Congress of Transportation and Transit, (2005).

7. Monteiro, E. A. F. Avaliação do Processo de Agendamento de Caminhões Transportadores de Granéis Sólidos Vegetais para Acesso aos Terminais Portuários: O Caso Porto de Santos. Master Dissertation in Transport, PPGT/ENC. T. DM-003A/2015, Departament of Civil and Environmental Engineering, Federal University of Brasília, Brasília, DF, 70 pp. (2015).

8. Bonoma, T. V., Case Research in Marketing: Opportunities, Problems, and a Process. Journal of Marketing Research, vol. 22, pp. 199-208, (1985).

9. Lazzarini, S. G. Estudo de caso: aplicabilidade e limitações do método para fins de pesquisa. Economia \& Empresa, vol. 2, n. 4, pp. 17-26, (1995).

10. Yin, R. K. Estudo de caso: Planejamento e Métodos. Porto Alegre, $5^{\mathrm{a}}$ ed Bookman Editora, (2015). 